\title{
The Relationship between Psychosocial Development and Liking of Children in Nurses Working in Pediatric Clinics
}

\author{
(D) Müjde Çalıkuşu İncekar¹, (1) Ayşe İpek Yangil2, (1) Gizem Kaya³, (1) Gamze Genç2, (1) Zehra Doğan4, \\ (1) Suzan Yıldız \\ 1istanbul Gedik University Faculty of Health Sciences, Department of Nursing, İstanbul, Turkey \\ 2ístanbul University-Cerrahpaşa, Florence Nightingale Faculty of Nursing, İstanbul, Turkey \\ ${ }^{3}$ Biruni University, Faculty of Health Sciences, Department of Nursing, İstanbul, Turkey \\ $4 \dot{I}_{z m i r}$ Katip Çelebi University Faculty of Health Sciences, Department of Pediatric Nursing, İzmir, Turkey
}

\begin{abstract}
Aim: This study was conducted to determine the relationship between psychosocial development and liking of children in nurses working in pediatric clinics.

Materials and Methods: This study was conducted as a descriptive and correlational study on 110 nurses working at two hospitals. Data were collected using an information form, the Modified Erikson Psychosocial Stage Inventory, and the Barnett Liking of Children scale. Descriptive statistical tests, Mann-Whitney U test, Kruskal-Wallis test, Pearson correlation and regression analysis and Cronbach's alpha were used in the data analysis stage.

Results: It was found that there was a positive, weak, and significant correlation between the liking of children and the subscales of trust, autonomy, industry, identity, and generativity $(p<0.05)$. At the same time, there was a very weak, positive, and significant correlation between the liking of children and the subscales of initiative and ego integrity $(p<0.05)$. No significant correlation was observed between the liking of children and the subscale of intimacy ( $p>0.05)$. It was observed that there was a weak correlation between the level of liking of children and the determinant variables of trust, autonomy, initiative, industry, identity, intimacy, generativity, and ego integrity $\left(R^{2}=0.133\right)$.
\end{abstract}

Conclusion: It was concluded that nurses' levels of trust and autonomy increased the level of liking of children.

Keywords: Child, developmental, love, nursing, pediatrics, psychology

\section{Introduction}

According to Erikson, human beings go through eight stages of development throughout their lifetime. Each stage of development has its distinctive developmental goals (1). In every stage, a positive feeling and a negative feeling (such as trust versus mistrust) or an element dissociate and mature.
The conflict between these two opposite feelings is the subject of the crisis that is peculiar to that stage. Towards the end of every stage, the dominant feeling becomes obvious $(2,3)$. One of the mostly accepted forms of unrequited love is to like a child. Children are valuable individuals whose all needs are met as best as possible by using the available facilities (4). 
Nurses should know that children have different psychological, physiological, and physical characteristics from adults, an underdeveloped but constantly developing process of comprehension, and different reactions and perceptions towards diseases according to their developmental characteristics and chronological age (5-8). They should also know that care needs to be provided according to the age and development level of the child using both verbal and non-verbal communication methods in accordance with familycentered care $(7,8)$.

A nurse's liking/disliking of children is important in terms of care and communication. The United Nations' Declaration of the Rights of the Child states, "A child needs love and understanding in order to develop her or his own identity fully and compatibly" (5). Therefore, in case of impairment of health during which the child needs love and attention most, it is an important need for her or him to be liked by nurses and other medical personnel. Nursing and especially nursing in pediatric clinics is grounded on the liking of children, empathy, and communication. Nurses' liking of children causes them to accept them more easily, enjoy spending time with them and be more careful and attentive in communication with them (9).

As is seen, there is evidence proving that if nurses who work with the child population have knowledge about children's development levels and like them, this will make a significant contribution to their care. It is important for nurses working in pediatric clinics to know not only children's development levels but also their own development levels in terms of interventions to be performed for children and the care-related approach. Studies conducted in Turkey have reported that nurses working in pediatric clinics have higher levels of liking children $(6,10,11)$. However, when examining the literature, there is no information about the psychosocial development levels of nurses working in pediatric clinics. In the literature, there is no evidence about whether or not development levels of nurses working in pediatric clinics affect their levels of liking children. It is thought that knowing nurses' development levels and levels of liking of children may be effective on the quality of care and formation of scientific evidences. For this reason, this study was conducted to determine nurses' psychosocial development and liking of children and reveal the relationship between these two concepts.

\section{Materials and Methods}

\section{Design, Sample and Setting}

This study was conducted in a descriptive and correlational design at two hospitals located in istanbul between February and March 2017. The population of the study consisted of 198 nurses working in pediatric clinics; whereas, the sample consisted of 110 (55.55\%) nurses who volunteered to participate in the study. All nurses at the hospitals who agreed to participate in the study were included in the study without making discrimination.

\section{Study Questions}

1-What are nurses' scores of psychosocial development?

2-What are nurses' scores of liking of children?

3-What is the relationship between nurses' scores of psychosocial development and scores of liking of children?

4-What is the relationship between nurses' sociodemographic characteristics and scores of psychosocial development?

5-What is the relationship between nurses' sociodemographic characteristics and scores of liking of children?

\section{Instruments}

Information Form for Nurses: The information form consisted of a total of 10 questions including four open ones and six closed ones for determining the socio-demographic characteristics of nurses.

The Modified Erikson Psychosocial Stage Inventory (MEPSI): The Erikson Psychosocial Stage Inventory (EPSI) was developed by Rosenthal, Gurney, and Moore in 1981 for the purpose of measuring Erikson's first six stages of development (trust, autonomy, initiative, industry, identity and intimacy). Internal consistency coefficients of the inventory vary between 0.57 and 0.75 (12). In the 80-item Modified Erikson Psychosocial Stage Inventory (MEPSI), which is the modified form of the EPSI and was developed by Darling-Fisher and Leidy (1988) (13); items of the six stages of development in the original inventory were modified and items aimed at measuring the stages of generativity and ego integrity were also added. The inventory was performed on healthy adults. Turkish validity and reliability of the MEPSI was conducted by Ozgungor and Acun Kapikiran (14). The MEPSI consists of a total of 10 items that measure five positive and five negative attitudes corresponding to successful and unsuccessful analyses for each stage. The inventory was developed as a five-point Likert scale consisting of the options from "strongly disagree" to "strongly agree". Reliability coefficients regarding the 
subscales of the inventory vary between 0.75 and 0.85 and the reliability coefficient of the overall inventory is 0.97 (13). In this study, the reliability coefficient of the inventory was found to be 0.92 .

The Barnett Liking of Children scale: This scale was developed by Barnett and Sinisi (15) in 1990. The Turkish validity and reliability study of the scale was conducted by Duyan and Gelbal (4). The scale includes 14 items and individuals are asked to express their opinions about each item in seven levels varying from "Strongly disagree" to "Strongly agree". Among the items aimed at determining "liking of children", four have a negative meaning (items $3,6,10$, and 13), whereas ten have a positive meaning. While high scores signify that people like children more, low scores signify that the level of liking of children is low. While the internal consistency coefficient of the Barnett Liking of Children scale was determined as 0.93 , the testretest reliability coefficient was determined as 0.91 (15). In this study, the reliability coefficient of the scale was found to be 0.88 .

\section{Data Collection}

Data collection tools were applied by the researchers conducting face-to-face interviews with nurses. The nurses who agreed to participate in the study filled in data collection forms independently from other nurses in a quiet and empty room for 15 minutes on average.

\section{Ethics}

In order to conduct the study, ethics committee approval from the İstanbul University Social and Human Sciences Ethics Committee (approval number: 2016/157), institutional permission from the hospitals, written consent from the nurses who agreed to participate in the study, and the necessary permission from the scale authors were obtained.

\section{Statistical Analysis}

The data obtained in the study were analyzed using the SPSS for Windows 22.0 program. In data assessment, number, percentage, mean, and standard deviation among descriptive statistical methods were used. While quantitative continuous data between two independent groups were compared using the Mann-Whitney $U$ test, quantitative continuous data between more than two independent groups were compared using the KruskalWallis test. Following the Kruskal-Wallis test, the MannWhitney $U$ test was used as a supplementary test for determining the differences. Pearson correlation, regression analysis and Cronbach's alpha were applied between continuous variables of the study. The data obtained were evaluated at a confidence interval of $95 \%$ and significance level of less than $5 \%$.

\section{Results}

\section{Descriptive Characteristics}

It was found that $90.9 \%$ of the nurses participating in the study were female, $9.1 \%$ were male and their average age was $29.47 \pm 6.56$ (minimum: 20, maximum: 51) years. When examining the educational background of the nurses, it was determined that $14.5 \%$ were high school graduates, $15.5 \%$ had an associate's degree, $56.4 \%$ had a bachelor's degree, and $13.6 \%$ had a master's degree. $50.9 \%$ of the nurses were married and $31.8 \%$ had children.

When examining the durations of the participating nurses working life in pediatric services, it was observed that they had worked for 5.45 \pm 5.16 (minimum: 0.08, maximum: 29) years on average and when considering their total duration of working in the profession, it was observed that they had worked for $7.73 \pm 6.55$ (minimum: 0.83 , maximum: 34 ) years on average. It was determined that the average weekly working hours of the nurses was $49.59 \pm 8.92$ (minimum: 40 , maximum: 80 ) hours. $49.1 \%$ of the nurses who participated in the study were working in intensive care units, $25.5 \%$ in internal medicine services, $14.5 \%$ in pediatric emergency services, $5.5 \%$ in pediatric surgery services and $5.5 \%$ in pediatric hematology services. When the nurses were asked about whether or not they liked the profession of nursing, $84.5 \%$ of them answered yes and $15.5 \%$ answered no.

\section{The Nurses' Psychosocial Development Levels and Levels of Liking of Children}

It was determined that while the nurses participating in the study had moderate levels of trust, they had very high levels of autonomy, initiative, industry, identity, intimacy, generativity, ego integrity and very high levels of liking of children (Table I).

\section{Comparing the Nurses' Psychosocial Development Levels and Descriptive Characteristics}

There was no significant difference between the nurses' psychosocial development levels and age ( $p>0.05)$. When examining nurses' psychosocial development levels based on their educational background, it was found that the nurses who were high school graduates had statistically significantly lower levels of trust and autonomy than those nurses with associate degrees, bachelor's degrees or master's degrees $(p=0.02, p=0.01)$. 
When examining the correlation between nurses' psychosocial development levels and duration of working in pediatric services, it was determined that the nurses who had worked in pediatric services for more than a year had significantly higher levels of trust $(p=0.01)$, identity $(p=0.01)$, autonomy $(p=0.02)$, and generativity $(p=0.03)$ subscales than nurses who had worked in pediatric services for less than a year. It was determined that the those nurses whose total duration of working in the profession was 6-10 years had higher scores of intimacy $(3.875 \pm 0.453)$ than those nurses whose total duration of working in the profession was 5 years and below $(3.593 \pm 0.416)$. When examining nurses' psychosocial development levels according to weekly working hours, it was determined that those nurses who worked for 60 hours and above had statistically significantly lower scores in the subscale of trust than those nurses who had worked for 40-59 hours a week $(p=0.00)$.

When examining whether or not the nurses' psychosocial development levels showed a significant difference in terms of the department where they worked, it was determined that those nurses working in intensive care units had higher scores in the subscale of trust than the nurses working in other departments $(p=0.01)$, and those nurses working in intensive care units and pediatric emergency departments had higher scores in the subscale of ego integrity than nurses working in the other departments $(p=0.03)$.

When examining the nurses' psychosocial development levels based on their state of liking their profession; it was found that those nurses who stated that they liked their profession had significantly higher mean scores in the subscales of trust $(p=0.00)$, initiative $(p=0.04)$, intimacy $(p=0.00)$, and ego integrity $(p=0.00)$ when compared

Table I. Modified Erikson Psychosocial Stage Inventory and Liking of Children Levels ( $n=110$ )

\begin{tabular}{|l|l|l|l|l|}
\hline MEPSI & Mean & SD & Minimum & Maximum \\
\hline Trust & 3.360 & 0.541 & 1.800 & 4.500 \\
\hline Autonomy & 3.839 & 0.405 & 2.900 & 4.800 \\
\hline Initiative & 3.896 & 0.412 & 2.900 & 5.000 \\
\hline Industry & 4.067 & 0.453 & 3.100 & 5.000 \\
\hline Identity & 3.906 & 0.432 & 2.700 & 5.000 \\
\hline Intimacy & 3.701 & 0.435 & 2.600 & 4.600 \\
\hline Generativity & 3.721 & 0.404 & 2.900 & 4.700 \\
\hline Ego integrity & 3.631 & 0.469 & 2.500 & 4.900 \\
\hline Liking of children & 86.555 & 12.375 & 41.000 & 98.000 \\
\hline
\end{tabular}

MEPSI: Modified Erikson Psychosocial Stage Inventory, SD: Standard deviation to those nurses who stated that they did not like their profession. Married nurses had lower scores of initiative compared to single nurses $(p=0.02)$. The nurses who had children had lower scores of initiative than the nurses who had no children $(p=0.01)$.

\section{Comparing the Nurses' Levels of Liking of Children and Descriptive Characteristics}

Table II shows the results of the relationship between the pediatric nurses' liking of children and some sociodemographic characteristics.

The Relationship between the Nurses' Psychosocial Development Levels and Levels of Liking of Children

When comparing the scores obtained by the nurses from the subscales of psychosocial development and the liking of children scale (Table III), it was found that there was a positive, weak, and significant correlation between liking of children and the subscales of trust, autonomy, industry, identity, and generativity $(p<0.05)$. Additionally, there was a very weak, positive, and significant correlation between liking of children and the subscales of initiative and ego integrity $(p<0.05)$. No significant correlation was observed between liking of children and the subscale of intimacy $(\mathrm{p}>0.05)$.

Regression analysis, which was conducted to determine the cause-effect relationship between liking of children and the scores obtained by the nurses from the subscales of trust, autonomy, initiative, industry, identity, intimacy, generativity, and ego integrity of MEPSI was found to be statistically significant ( $F=3.088 ; p=0.004)$. It was observed that there was a weak correlation (the explanatory power) between the level of liking of children and the determinant variables of trust, autonomy, initiative, industry, identity, intimacy, generativity, and ego integrity $\left(R^{2}=0.133\right)$. It was determined that nurses' levels of trust $(B=5.632)$ and autonomy $(\beta=6.819)$ increased their levels of liking of children (Table IV).

\section{Discussion}

\section{Comparing the Nurses' Psychosocial Development Levels and Descriptive Characteristics}

In this study, it was determined that the nurses had moderate scores on the trust subscale and high scores on the other seven subscales in the MEPSI. Erikson believes that the sum of trust which consists of infancy experiences depends not only on the quantity of food given or demonstrations of love, but mainly on the quality of the relationship with their mother (1). In the first year of life, an infant's psychosocial 
duty is to learn to trust. The sense of trust arising from the relationship between the mother and infant forms the basis of an infant's future interpersonal relations (16).

In this study, there was no statistically significant difference between the nurses' psychosocial development levels and age. Among nurses who participated in the study; high school graduates had lower scores of trust and autonomy, which are the subscales of psychosocial development, compared to those nurses with associate degrees, bachelor's degrees or master's degrees. It has been reported that at least a bachelor's degree is required in order for nursing to acquire professionalization (17). It may be thought that an increase in educational level affects positively the nurses' levels of trust and autonomy.

Table II. The Relationship between the Nurses' Liking of Children and some socio-demographic characteristics

\begin{tabular}{|c|c|c|c|c|c|c|c|}
\hline & Group & n & Mean & SD & Test value & $p$ value & Difference \\
\hline \multirow{4}{*}{ Age } & $20-25(1)$ & 37 & 80.243 & 15.016 & \multirow{4}{*}{$20.104^{*}$} & \multirow{4}{*}{0.000} & \multirow{4}{*}{$\begin{array}{l}3>1 \\
4>1 \\
3>2 \\
4>2\end{array}$} \\
\hline & $26-30(2)$ & 32 & 86.375 & 11.542 & & & \\
\hline & $31-35(3)$ & 18 & 91.778 & 7.689 & & & \\
\hline & Over 35 (4) & 23 & 92.870 & 5.039 & & & \\
\hline \multirow{4}{*}{ Education } & High school (1) & 16 & 82.813 & 14.833 & \multirow{4}{*}{$3.770^{*}$} & \multirow{4}{*}{0.287} & \multirow{4}{*}{-} \\
\hline & Associate's degree (2) & 17 & 84.412 & 14.111 & & & \\
\hline & Bachelor's degree (3) & 62 & 86.919 & 12.102 & & & \\
\hline & Master's degree (4) & 15 & 91.467 & 6.545 & & & \\
\hline \multirow{4}{*}{$\begin{array}{l}\text { Durations of working in } \\
\text { pediatric services }\end{array}$} & Less than 1 year (1) & 10 & 84.600 & 9.442 & \multirow{4}{*}{$13.738^{*}$} & \multirow{4}{*}{0.003} & \multirow{4}{*}{$\begin{array}{l}3>1 \\
4>1 \\
3>2 \\
4>2\end{array}$} \\
\hline & $1-5$ years $(2)$ & 58 & 83.879 & 13.321 & & & \\
\hline & $6-10$ years $(3)$ & 31 & 89.613 & 11.899 & & & \\
\hline & 10 years or more (4) & 11 & 93.818 & 4.535 & & & \\
\hline \multirow{3}{*}{$\begin{array}{l}\text { Total duration of working in } \\
\text { the profession }\end{array}$} & 5 years or less (1) & 53 & 83.019 & 13.082 & \multirow{3}{*}{$15.442^{*}$} & \multirow{3}{*}{0.000} & \multirow{3}{*}{$\begin{array}{l}2>1 \\
3>1\end{array}$} \\
\hline & 6-10 years $(2)$ & 32 & 87.656 & 12.630 & & & \\
\hline & 10 years or more $(3)$ & 25 & 92.640 & 7.135 & & & \\
\hline \multirow{4}{*}{ Weekly working hours } & 40 hours (1) & 27 & 91.259 & 6.820 & \multirow{4}{*}{$16.051^{*}$} & \multirow{4}{*}{0.001} & \multirow{4}{*}{$\begin{array}{l}1>3 \\
1>4 \\
2>3 \\
2>4\end{array}$} \\
\hline & $41-50$ hours (2) & 52 & 88.231 & 12.264 & & & \\
\hline & $51-60$ hours (3) & 18 & 79.556 & 13.232 & & & \\
\hline & 60 hours or more (4) & 13 & 79.769 & 14.754 & & & \\
\hline \multirow{5}{*}{ Working area } & Internal medicine services (1) & 28 & 87.321 & 10.488 & \multirow{4}{*}{$13.274^{*}$} & \multirow{4}{*}{0.010} & \multirow{4}{*}{$\begin{array}{l}1>2 \\
3>2 \\
4>2\end{array}$} \\
\hline & $\begin{array}{l}\text { Pediatric emergency services } \\
(2)\end{array}$ & 16 & 80.625 & 10.905 & & & \\
\hline & Intensive care units (3) & 54 & 88.500 & 12.661 & & & \\
\hline & Pediatric surgery services (4) & 6 & 91.833 & 7.055 & & & \\
\hline & $\begin{array}{l}\text { Pediatric hematology services } \\
(5)\end{array}$ & 6 & 76.000 & 17.754 & - & - & - \\
\hline \multirow{2}{*}{$\begin{array}{l}\text { Whether or not liked the } \\
\text { profession }\end{array}$} & Yes & 93 & 88.054 & 10.863 & \multirow{2}{*}{$482.500^{* *}$} & \multirow{2}{*}{0.011} & \multirow{2}{*}{-} \\
\hline & No & 17 & 78.353 & 16.740 & & & \\
\hline \multirow{2}{*}{ Marital status } & Married & 56 & 91.018 & 7.721 & \multirow{2}{*}{$841.000^{* *}$} & Pी & \\
\hline & Single & 54 & 81.926 & 14.499 & & 0.000 & 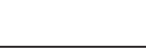 \\
\hline & Yes & 35 & 91.600 & 7.441 & & & \\
\hline ПIaving chituren & No & 75 & 84.200 & 13.509 & 020.500 & 0.002 & - \\
\hline
\end{tabular}

${ }^{*} \mathrm{KW},{ }^{* *} \mathrm{MW}$

SD: Standard deviation 
In this study, it was found that those nurses who had worked in the pediatric services for more than one year had higher scores of trust, autonomy, identity and generativity subscales than those nurses who had worked for less than one year. In addition, it was determined that those nurses who had worked in the profession for six years or more had significantly higher scores on the intimacy subscale than those nurses who had worked for five years or less. It is thought that this result is compatible with the study which reports that as the year of experience in nursing increases, professionalism and critical thinking power increase (18).

In this study, it was determined that those nurses in pediatric clinics who worked for 60 hours or more per week had statistically significant lower scores in the subscale of trust. According to the regulations, the weekly working hour of nurses in Turkey is required to be 40 hours (19). Since long-duration working causes nurses to experience attention deficit and fatigue and consequently have a higher risk of making mistakes, the ideation of creating an inappropriate environment for the patients they provide care for and their own security might have affected the subscale of trust in the MEPSI.

In this study, it was determined that those nurses working in intensive care units had higher scores on the trust subscale than those nurses working in the other departments (internal medicine, pediatric emergency department, pediatric surgery, and hematology) and those nurses working in intensive care units and emergency departments also had higher scores on the ego integrity subscale. Nurses working in intensive care units have an important position in shaping the future of safe and quality care. Ambitious and professional nurses who are organized in these units are able to provide a top-level health care service (20). This condition increases the trust of nurses in both themselves and their circle. In addition, nurses encountering complex cases and having the ability to provide a high level of care to these cases increases their accumulation of knowledge and allows them to have higher autonomy than those nurses who work in the other clinics. It may be thought that such factors have a positive effect on these nurses' scores of trust and ego integrity.

In this study, those nurses who liked their profession had statistically significantly higher scores of trust, initiative, intimacy, and ego integrity subscales than those who stated that they did not like their profession. Married nurses had significantly lower scores on the initiative subscale than single nurses. In addition, those nurses who had children had statistically significantly lower scores on the initiative subscale than those nurses who had no children. Karamanoglu et al. (21), reported that nurses who liked their profession had higher professional attitudes than those who did not. When nurses perform their duties professionally and willingly, their levels of trust, initiative, intimacy, and ego integrity are affected

Table III. The Relationship between the Nurses' Psychosocial Development Levels and Levels of Liking of Children

\begin{tabular}{|l|l|l|l|l|l|l|l|l|l|}
\hline & \multicolumn{8}{|l|}{ Psychosocial development subscales (MEPSI) } \\
\cline { 2 - 11 } & & Trust & Autonomy & Initiative & Industry & Identity & Intimacy & Generativity & Ego integrity \\
\hline \multirow{2}{*}{$\begin{array}{l}\text { Liking of } \\
\text { children }\end{array}$} & $\mathrm{r}$ & 0.341 & 0.332 & 0.198 & 0.340 & 0.272 & 0.181 & 0.266 & 0.246 \\
\cline { 2 - 11 } & p value & 0.000 & 0.000 & 0.038 & 0.000 & 0.004 & 0.059 & 0.005 & 0.010 \\
\hline
\end{tabular}

MEPSI: Modified Erikson Psychosocial Stage Inventory

Table IV. The effect of psychosocial development Levels of Nurses on Liking of Children

\begin{tabular}{|c|c|c|c|c|c|c|c|}
\hline Dependent variable & Independent variable & ß & $\mathbf{t}$ & $p$ value & $F$ & Modal (p) & $\mathbf{R}^{2}$ \\
\hline \multirow{9}{*}{ Liking of Children } & Stable & 42.607 & 3.400 & 0.001 & \multirow{9}{*}{3.088} & \multirow{9}{*}{0.004} & \multirow{9}{*}{0.133} \\
\hline & Trust & 5.632 & 2.362 & 0.020 & & & \\
\hline & Autonomy & 6.819 & 2.140 & 0.035 & & & \\
\hline & Initiative & -5.907 & -1.274 & 0.206 & & & \\
\hline & Industry & 4.500 & 1.079 & 0.283 & & & \\
\hline & Identity & 1.065 & 0.261 & 0.795 & & & \\
\hline & Intimacy & -1.886 & -0.582 & 0.562 & & & \\
\hline & Generativity & -0.953 & -0.234 & 0.816 & & & \\
\hline & Ego integrity & 2.378 & 0.724 & 0.471 & & & \\
\hline
\end{tabular}


positively. Those nurses who are married and have children have responsibilities towards their spouse and children at home. Thus, they may have lower levels of initiative than the other group.

\section{Comparing the Nurses' Levels of Liking of Children and Descriptive Characteristics}

Every child needs love in order to acquire the basic sense of trust and develop her or his personality fully and compatibly. On the other hand, hospitalization may disrupt this situation. Especially hospitalized children may perceive their condition as a punishment and think that they are liked less. There is an important need for them to be liked especially by nurses in pediatric clinics who are the primary caregivers in cases of disease and hospitalization (5). It is significant for nurses in pediatric clinics to have the characteristics of liking children, communicating with children, interacting with children and showing patience, concern, flexibility, kindness and tranquility (11).

In a previous study, the nurses' mean score of liking of children was found to be $82.07 \pm 16.35$ (6). In another study, this mean score was observed to be $82.81 \pm 13.00$ (10). In yet another study, the value was indicated to be $84.35 \pm 13.29$ (11). In this study, the mean score was determined to be $86.55 \pm 12.37$. According to the results of these studies conducted in Turkey, it can be seen that nurses have high levels of liking of children. In addition, it may be considered that nurses who like children prefer to work with children.

When examining the literature $(6,10,11)$; no significant correlation between the score of liking of children and age was reported. In this study, on the other hand, it was concluded that nurses who were older than 31 had higher scores of liking of children than nurses from the other age groups. As a nurse's age increases, their views on events and levels of enduring, tolerating or bearing events may increase. It can be considered that the increase of clinical experience in parallel with increasing age may increase their communication with children and pave the way for liking them more. When nurses' educational background and scores of liking of children were examined, no significant correlation was observed between the variables, which shows a parallelism with the literature $(6,10)$. It may be considered that nurses like children independently from their educational background.

The Relationship between the Nurses' Psychosocial Development Levels and Levels of Liking of Children

In this study, it was concluded that there were positive weak correlations between the nurses' scores of liking of children and their scores of trust, autonomy, industry, identity, and generativity subscales of psychosocial development and a very weak positive correlation between their scores of liking of children and the subscales of initiative and ego integrity; however, there was no significant correlation between their scores of liking of children and the subscale of intimacy. It was determined that the nurses' liking of children had a weak correlation with eight of the subscales of the MEPSI. It was found that the trust and autonomy subscales of the MEPSI increased with the level of liking of children.

\section{Study Limitations}

The sample of this study is limited to nurses working in pediatric clinics of only two hospitals included in the study. Examining the forms used as data collection tool only based on the statements of the sample group is another limitation. However, the strength of the study is that the validity and reliability studies of the scales used in the study were conducted.

\section{Conclusion}

It was determined that the nurses had high psychosocial development levels except for the subscale of trust, very high levels of liking of children, there was a weak but positive correlation between psychosocial development and liking of children except for the subscale of intimacy and the levels of trust and autonomy, which are among psychosocial development stages, increased with the level of liking of children. The level of psychosocial development of nurses working in pediatrics clinics will help them to love children more. Increasing the levels of trust and autonomy of nurses working especially in pediatric clinics will contribute to increasing the love of children and offering more loving care. In addition, the branch selection of nurses working in pediatric clinics can make a positive contribution to the quality of nursing care. Determination of the levels of liking of children of nurses who intend to work in the pediatric clinics will also be effective on their major selection.

\section{Acknowledgements}

We offer our appreciation to the nurses who participated in this research.

\section{Ethics}

Ethics Committee Approval: In order to conduct the study, ethics committee approval from the İstanbul University Social and Human Sciences Ethics Committee (approval number: 2016/157). 
Informed Consent: Written consent from the nurses who agreed to participate in the study, and the necessary permission from the scale authors were obtained.

Peer-review: Externally peer-reviewed.

\section{Authorship Contributions}

Concept: M.Ç.I., S.Y., Design: M.Ç.I., S.Y., Data Collection or Processing: A.I.Y., G.G., G.K., Analysis or Interpretation: M.Ç.I., A.I.Y., G.G., G.K., Literature Search: M.Ç.I., Writing: M.Ç.I., S.Y., Z.D.

Conflict of Interest: The authors have no conflicts of interest relevant to this article to disclose.

Financial Disclosure: The authors have no financial relationships relevant to this article to disclose.

\section{References}

1. Erikson EH. The life cycle completed (extended version). New York 1997: W. W. Norton (Originally published in 1982).

2. Ozdemir O, Guzel Ozdemir P, Kadak MT, Nasiroglu S. Personality development. Current Approaches in Psychiatry 2012;4:566-89.

3. Fleming JS. 9. Erikson's Psychosocial Developmental Stages. In Psychological perspectives on human development 2004 http://swppr.org/textbook/contents.html (Access: 22.07.2017).

4. Duyan V, Gelbal S. The adaptation study of barnett liking of children scale to Turkish. Education and Science 2008;33:40-8.

5. Hockenberry MJ, Wilson D. Wong's nursing care of infants and children. Ninth Edition, America, Elsevier Mosby Company 2011;10-5.

6. Erdem $Y$, Duyan $V$. A determination of the factors that affect the level of pediatric nurses' liking of children. Turk I Med Sci 2011;41:295-305.

7. Sen Beytut D, Bolisik B, Solak U, \& Seyfioglu U. A study of the influences of hospitalization on children through drawing as a projective method. Maltepe University Journal of Nursing Science and Art 2009;2:35-44.
8. Brown $J \mathrm{H}$, Fosket $\mathrm{NH}$. Career desirability: young people's perception of Nursing as a career. I Adv Nurs 1999;29:1342-50.

9. Akgun Kostak M. Nursing and midwifery students' state of liking of children, effects of paediatrics nursing lesson on the state of liking of children and affecting factors. Cumhuriyet Nursing Journal 2013;2:50-6.

10. Kara S. Impact of love of children to the communication skills of nurses work with children in Kocaeli Province. Unpublished Master Thesis Istanbul, 2014.

11. Tural Buyuk E, Rizalar S, Seferoglu EG, Oguzhan H. Analysing liking of children and parenting attitudes of nurses working in pediatric and adult clinics. The Journal of Pediatric Research 2014;1:130-7.

12. Rosenthal D, Gurney RM, Moore SM. From trust to intimacy: $A$ new inventory for examining Erikson's stages of psychosocial development. Journal of Youth and Adolescence 1981;10:525-37.

13. Darling-Fisher CS, Leidy NK. Measuring Eriksonian development in the adult: The modified Erikson psychosocial stage inventory. Psychological Reports 1988;62:747-54.

14. Ozgungor S, Acun Kapikiran N. Comparisive adaptation of Erikson psychosocial stage inventories to Turkish culture: primary results. Turkish Psychological Counselling and Guidance Journal 2011;4:114-26.

15. Barnett MA, Sinisi CS. The initial validation of a Liking of Children Scale. Journal of Personality Assessment 1990;55:161-7.

16. Yavuzer H. Parents and Children. Istanbul 1986: Remzi Kitabevi.

17. Karadag A. Nursing as A Profession. Journal of Anatolia Nursing and Health Sciences 2002;5:1-8.

18. Adams BL. Nursing education for critical thinking: an integrative review. I Nurs Educ 1999;38:111-9.

19. 657 Law on Civil Servants of the Year. Official newspaper, 12056, 23.07.1965. http://www.mevzuat.gov.tr/MevzuatMetin/1.5.657. pdf Access: 25.07.2017

20. Hatipoglu S. The Principles of Surgery Intensive Care Nursing. Gülhane Medical Journal 2002;44:475-9.

21. Karamanoglu AY, Ozer FG, Tugcu A. Evaluation of surgical ward nurses professionalism in their work, in Denizli. Firat Medical Journal 2009;14:12-7. 